\title{
Analisis Kadar Magnesium dan Kalium pada Garam Rich Minerals
}

\author{
Ary Giri Dwi Kartika ${ }^{1)}$ Wiwit Sri Werdi Pratiwi' ${ }^{2)}$, Novi Indriyawati3), Onie Wiwid Jayanthi4) \\ ${ }^{1,2,3,4)}$ Program Studi Ilmu Kelautan, Fakultas Pertanian, Universitas Trunojoyo Madura \\ 2)Pusat Unggulan IPTEK (PUI) Garam \\ 1)arygiri.dwikartika@trunojoyo.ac.id 2)wiwit.swiper@gmail.com
}

DOI: http://dx.doi.org/10.21107/rekayasa.v12i1.5094

\begin{abstract}
ABSTRAK
Pemenuhan sumber mineral dalam makanan yang seimbang mampu menunjang tercapainya kondisi tubuh yang sehat. Garam rich minerals selain digunakan sebagai bumbu dan penyedap makanan, merupakan salah satu sumber mineral yang dibutuhkan oleh tubuh. Kombinasi Kandungan $\mathrm{NaCl}$ dan berbagai mineral lainnya yang tidak dihilangkan dalam proses produksi garam rich minerals mampu menjaga keseimbangan elektrolit dalam tubuh demi mempertahankan komposisi keseluruhan fungsi tubuh. Pada penelitian ini, garam rich minerals dihasilkan dari proses penguapan air laut bebas kontaminasi dan tidak menghilangkan berbagai mineral lainnya yang terkandung di dalam air laut. Setiap $1000 \mathrm{ml}$ air laut yang direbus menghasilkan rata-rata 34 gram kristal garam. Data analisis kimia menunjukan kadar air sebesar $5 \%, \mathrm{NaCl}$ sebesar $88 \%$; kalium sebesar $0.024 \%$ serta magnesium sebesar $0.476 \%$. Dari data tersebut garam rich minerals memenuhi SNI syarat mutu garam gurih.
\end{abstract}

Kata kunci: Garam, Rich Minerals, Magnesium, Kalium

\section{Analysis of Magnesium and Potassium Content in Rich Minerals Salt}

\begin{abstract}
The Fulfillment of mineral resources in balanced food can support the achievement of a healthy body condition. Rich minerals salt is one of the sources of minerals needed by the body beside it being used as a food seasoning and flavoring. The combination of $\mathrm{NaCl}$ content and various other minerals that are not removed in the production process of rich minerals can maintain the electrolyte balance in the body to maintain the overall composition of body functions. In this study, rich mineral salts were produced from contamination-free seawater evaporation processes and did not eliminate various other minerals contained in seawater. Every $1000 \mathrm{ml}$ of boiled sea water produces an average of 34 grams of salt crystals. Chemical analysis data showed a water content of 5\%; $\mathrm{NaCl} 88 \%$; potassium $0.024 \%$ and magnesium $0.476 \%$. From that data, rich minerals salt fulfill savory salt quality requirements by SNI.
\end{abstract}

Keywords : Salt, Rich Minerals, Magnesium, Potassium

\section{PENDAHULUAN}

Mineral merupakan komponen anorganik, komponen jaringan tubuh dan komponen cairan tubuh yang bekerjasama dengan enzim, hormon, vitamin serta bahan transport lainnya. Mineral memiliki fungsi dalam pemeliharaan jaringan dan fungsi tubuh, pemeiharaan keseimbangan asam basa dalam tubuh serta berperan dalam proses metabolisme tubuh.

\section{Article History:}

Received: 26 Maret 2019; Accepted: 1 April 2019

ISSN: 2502-5325 (Online) Terakreditasi Peringkat 4 oleh

Kementerian Riset, Teknologi dan Pendidikan Tinggi (ARJUNA),

berdasarkan Keputusan Direktur Jenderal Penguatan Riset dan

Pengembangan Nomor: 21/E/KPT/2018 tanggal 9 Juli 2018
Dalam sistem fisiologi tubuh manusia, mineral dibagi menjadi dua, yaitu: (1.) mineral makroelemen ( $>100 \mathrm{mg} /$ hari) meliputi kalsium (Ca), fosfor $(P)$, kalium $(K)$, sulfur $(S)$, natrium $(\mathrm{Na})$, klor $(\mathrm{Cl})$ dan magnesium $(\mathrm{Mg})$; (2.) mineral mikroelemen ( $<100 \mathrm{mg} / \mathrm{hari})$, meliputi besi $(\mathrm{Fe})$, lodium $(\mathrm{I})$, seng $(\mathrm{Zn})$, mangan $(\mathrm{Mn})$, selenium ( $\mathrm{Se}$ ) dan Kromium ( $\mathrm{Cr}$ ). Mineral-mineral tersebut tidak dapat disintesis di dalam

\section{Cite this as:}

Kartika, A., Pratiwi, W., Indriawati, N., \& Jayanthi, O. (2019).

Analisis Kadar Magnesium dan Kalium pada Garam Rich

Minerals. Rekayasa, 12(1), 1-4. doi:http://dx.doi.org/10.21107/ rekayasa.v12i1.5094 
tubuh manusia, sehingga harus disuplai dari makanan bergizi untuk memenuhi minimal angka kecukupan gizi tiap individu (Devi, 2010).

Garam dapur yang selama ini digunakan oleh masyarakat umum sebagai bumbu dan penyedap rasa pada makanan, merupakan garam yang diproduksi dari air laut dengan menghilangkan mineral lain agar mendapatkan kadar natrium klorida lebih dari 94 $\%$ (BSN, 2010). Oleh karena itu, dibutuhkan inovasi produk garam kaya mineral dengan cara tanpa menghilangkan mineral-mineral yang ada pada air laut yang akan digunakan sebagai bahan bakunya.

Garam rich minerals merupakan salah satu garam konsumsi yang didapatkan dari penguapan air laut bebas kontaminan, dimana selama proses produksinya tidak menghilangkan unsur-unsur mineral yang terkandung di air laut tersebut. Oleh karena itu, kualitas mineral yang terkandung dalam garam rich minerals sangat bergantung dari kondisi air laut serta proses evaporasi yang terjadi. Hal inilah yang membuat garam rich minerals memiliki rasa, tektur dan warna yang berbeda-beda. Selain Natrium klorida, yang berfungsi mengatur denyut jantung dan memelihara keseimbangan $\mathrm{pH}$ dalam tubuh, garam rich minerals kaya akan magnesium yang bermanfaat untuk mengatur ratusan proses biokimia dalam system metabolism dan kardiovaskuler; kalium yang penting bagi sistem saraf; zat besi dan sulfur yang mendukung sistem imun dan menstabilkan kondisi tubuh. Kombinasi kandungan mineral yang terdapat dalam garam rich minerals mampu menjaga keseimbangan elektrolit dalam tubuh demi mempertahankan komposisi dan sirkulasi darah, kekuatan otot serta keseluruhan fungsi tubuh (Nirmala, 2010; Rismawati, 2012). Berdasarkan peraturan Menteri Kesehatan RI nomor $30 / 2013$, batas konsumsi garam per orang/ hari adalah adalah 2000 miligram natrium atau setara dengan 5 gram garam dapur (Kemenkes 2013). Pada penelitian ini, garam rich mineral dihasilkan dari perebusan air laut bebas kontaminasi, dianalisis kadar air, $\mathrm{NaCl}$ serta mineral magnesium dan kalium.

\section{METODE PENELITIAN}

\section{Pembuatan Garam Rich Minerals}

Sampel air laut diambil di perairan laut Dusun Kotasek, Desa Tanjung, Kec. Pademawu, Kabupaten Pamekasan dengan garis lintang

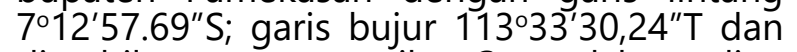
diambil saat pasang tiba. Sampel kemudian dibawa ke Laboratorium garam program studi ilmu kelautan universitas Trunojoyo Madura untuk diproses menjadi garam rich minerals. Setiap Air laut $(1000 \mathrm{ml})$ direbus dengan menggunakan hot plate $\left(T= \pm 120^{\circ} \mathrm{C}\right)$ sehingga menjadi kristal garam.

\section{Analisa Kadar Air garam}

Sampel garam dihaluskan dengan mortar dan penumbuk, kemudian ditimbang beratnya. Selanjutnya sampel garam di panaskan pada suhu $100-105^{\circ} \mathrm{C}$ selama $3-5$ jam. Setelah itu, sampel didinginkan di dalam desikator. Sampel dipanaskan kembali selama 30 menit setelah didinginkan sampel ditimbang. Kadar air didapatkan dari selisih antara berat awal sebelum pemanasan dan berat sampel sesudah pemanasan (AOAC, 1970)

\section{Analisa Kadar $\mathrm{NaCl}$}

Analisa kadar $\mathrm{NaCl}$ dilakukan berdasarkan SNI 01-3556 (2000). Sebanyak 50 gr sampel dilarutkan ke dalam $200 \mathrm{~mL}$ akuades kemudian disaring dengan menggunakan kertas saring. Sampel yang telah disaring diambil sebanyak $2 \mathrm{~mL}$ kemudian ditambahkan $1 \mathrm{~mL}$ K2CrO4 dan 5 tetes metil red. Titrasi larutan sampel dengan menggunakan AgNO3 hingga terbentuk warna merah bata.

\section{Analisis Kadar Magnesium}

Analisa kadar Magnesium dilakukan berdasarkan SNI 06-6989.12 (2004). Sebanyak 50 gr sampel dilarutkan ke dalam $200 \mathrm{~mL}$ akuades. larutan sampel tersebut kemudian disaring dengan menggunakan kertas saring. sebanyak $100 \mathrm{~mL}$ larutan sampel yang telah disaring ditambahkan $2 \mathrm{~mL} \mathrm{HCl}$ dan dipanaskan hingga kering kemudian ditambahkan $1 \mathrm{~mL}$ larutan klorida. Pembuatan larutan baku magnesium $100 \mathrm{ml} / /$ dilakukan dengan mengambil $10 \mathrm{~mL}$ larutan standar magnesium (1000 ml/l) dimasukan ke dalam labu ukur 100 mL, kemudian diencerkan dengan menggunakan akuades hingga tanda terra. Pembuatan larutan baku magnesium $10 \mathrm{mg} / \mathrm{l}$ dilakukan dengan memipet $50 \mathrm{~mL}$ larutan standar magnesium (1000 $\mathrm{ml} / \mathrm{l})$ ke adalam labu ukur $100 \mathrm{~mL}$ kemudian diencerkan menggunakan akuades hingga batas tera. Pembuatan larutan kerja magnesium dilakukan dengan memipet larutan baku magnesium $10 \mathrm{ml} / \mathrm{l}$ ke dalam labu ukur $100 \mathrm{~mL}$ kemudian diencerkan dengan akuades hingga batas tera. Larutan kerja magnesium diukur kadar magnesiumnya dengan menggunakan spektrofotometri serapan atom (SSA) pada panjnag gelombang 285,2 nm. Kadar magnesium didapatkan dari:
Kadar Mg $(\mathrm{mg} / \mathrm{l})=\mathrm{C} \times \mathrm{fp}$
Keterangan:
C : kadar hasil pengukuran
$\mathrm{fp}$ : faktor pengenceran 


\section{Analisis Kadar Kalium}

Analisa kadar kalium dilakukan berdasarkan Rochmawati et. al (2015). $\mathrm{HNO}_{3}$ dan $\mathrm{HClO}_{4}$ ditambahkan pada larutan sampel garam hingga terbentuk endapan. Kemudian, larutan tersebut disaring dengan menggunakan kertas saring. Larutan standar Kalium dibuat dengan berbagai konsentrasi yaitu 0,$5 ; 1,5 ; 2$ dan 3 ppm. Selanjutnya masing-masing konsentrasi diukur absorbansinya kemudian buat kurva sehingga didapatkan persamaan linier dari kurva tersebut. Pembuatan larutan uji dilakukan dengan melarutkan garam dengan menggunakan aquades kemudian ditambahkan $\mathrm{HNO}_{3}$, selanjutnya disaring dan diukur absorbansinya dengan menggunakan SSA. Kadar kalium didapatkan dengan mensubtisusikan nailai absorbansi larutan uji ke dalam persamaan linier kurva.

\section{HASIL DAN PEMBAHASAN}

\section{Produksi Garam Rich Minerals}

Kristal garam rich minerals (Gambar 1) diproduksi dari perebusan air laut (1000 ml) dengan suhu $\left(T= \pm 120^{\circ} \mathrm{C}\right)$ selama 2 hari sehingga menghasilkan Kristal garam rata-rata 34 gram. Air laut yang digunakan merupakan air laut yang bebas kontaminasi, jauh dari daerah pencemaran udara, laut maupun lingkungan sekitar.

Produksi garam rich minerals berbeda dengan produksi garam konsumsi pada umumnya, karena pada garam rich minerals, kandungan mineral yang ada di air laut tidak dihilangkan selama proses kristalisasi, proses yang demikian disebut kristalisasi total, sedangkan pada garam konsumsi (garam dapur) menggunakan prinsip kristalisasi bertingkat, dimana proses evaporasi dilakukan di beberapa kolam (Purbani, 2013; Effendy, 2012). Hal ini bertujuan untuk mengendapkan mineral mineral seperti besi oksida $\left(\mathrm{Fe}_{2} \mathrm{O}_{3}\right)$ yang mengendap pada $7^{\circ} \mathrm{Be}$, kalsium karbonat $\left(\mathrm{CaCO}_{3}\right)$ yang mengendap pada $16.75^{\circ} \mathrm{Be}$, Kalsium sulfat $\left(\mathrm{CaSO}_{4}\right)$ yang mengendap pada $20.60^{\circ} \mathrm{Be}$, sehingga nantinya menghasilkan kadar $\mathrm{NaCl}$ diatas $94 \%$ (BSN, 2010; PT Garam, 2018; Usiglio, 1849)

Tabel 1. Hasil Analisis Kandungan Kimia Garam Rich Minerals

\begin{tabular}{ccc}
\hline No & Kandungan & Kadar (\%) \\
\hline 1. & Air & 5 \\
2. & $\mathrm{NaCl}$ & 88 \\
3. & $\mathrm{~K}$ & 0,024 \\
4. & $\mathrm{Mg}$ & 0,476 \\
\hline
\end{tabular}

Garam rich minerals yang dihasilkan pada penelitian ini berwarna putih bersih dan bertekstur halus. Hasil analisis kimia garam rich minerals tersaji pada Tabel 1.

\section{Analisis Kadar Air}

Kadar air pada bahan pangan merupakan salah satu karakteristik yang penting, karena dapat mempegaruhi penampakan, tektur dan cita rasa pada bahan pangan. Pada penelitian ini, kadar air pada garam rich minerals sebesar 5 \%. (Tabel 1). Hasil uji tersebut memenuhi SNI syarat mutu garam konsumsi beryodium, dimana jumlah kadar air yang diperbolehkan maksimal sebesar 7\% (BSN, 2010).

\section{Analisis Kadar $\mathrm{NaCl}$}

Pada penelitian ini, garam rich minerals mengandung kadar $\mathrm{NaCl}$ sebesar $88 \%$ (Tabel 1). Hasil tersebut tidak memenuhi SNI syarat mutu garam konsumsi beryodium, dengan kadar $\mathrm{NaCl}$ pada garam minimal 94\%, tetapi kadar $\mathrm{NaCl}$ garam rich minerals ini memenuhi SNI syarat mutu garam gurih, dengan kadar $\mathrm{NaCl}$ minimal $87 \%$ (BSN, 1999). Selama ini, garam gurih yang dimaksud, merupakan paduan dari garam halus yang disalut dengan monosodium glutamate sehingga menghasilkan paduan rasa asin dan gurih (Nafi, 2014). Sedangkan, pada penelitian ini, garam rich minerals tidak ada campuran bahan kimia, tetapi mampu menghasilkan rasa asin dan gurih karena kombinasi kandungan $\mathrm{NaCl}$ dan berbagai mineral lainnya yang tidak dihilangkan selama proses produksi. Selain itu, kombinasi tersebut dapat menjaga keseimbangan elektrolit dalam tubuh.

Garam rich minerals mengandung kadar $\mathrm{NaCl}$ yang lebih rendah dibandingkan garam konsumsi pada umumnya, hal ini dikarenakan tujuan memproduksi garam rich minerals untuk mendapatkan garam dengan kadar $\mathrm{NaCl}$ yang rendah serta mengandung berbagai mineral lainnya yang dibutuhkan oleh tubuh. Garam rich minerals dapat pula digunakan kepada penderita hipertensi yang membutuhkan garam dengan kadar $\mathrm{NaCl}$ rendah.

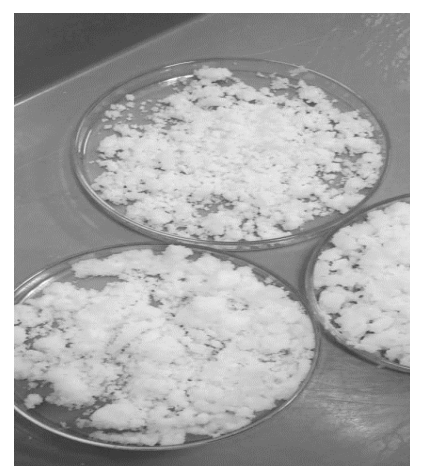

Gambar 1. Garam Rich Minerals 
Antonio (2013) menjelaskan tentang metode preparasi low sodium salt yaitu : (1) mengandung $\mathrm{NaCl}$ dan garam rangkap schoenite (K2SO4.MgSO4.6H2O) yang merupakan mineral sulfat, didapat dari batuan pegunungan aktif, dan kadar $\mathrm{NaCl}$ yang digunakan bervariasi antara 10 sampai $80 \%$ dari berat total; (2) mengandung $\mathrm{NaCl}$ dan garam rangkap glaserite (3K2SO4.Na2SO4), dan kadar $\mathrm{NaCl}$ antara 25 sampai $60 \%$ dari berat total; (3) mengandung $\mathrm{NaCl}, \mathrm{MgSO} 4$ dan $\mathrm{K} 2 \mathrm{SO} 4$; mengandung $\mathrm{NaCl}$, bittern dan kainite (K2SO4. MgSO4. MgCl2.6H2O); dan (4) mengandung $\mathrm{NaCl}, \mathrm{K} 2 \mathrm{SO} 4$ dan $\mathrm{Na} 2 \mathrm{SO} 4$.

\section{Analisis Kadar Kalium}

Garam rich minerals mengandung mineral kalium sebesar $0.024 \%$ (Tabel 1 ), setara dengan $0.813 \mathrm{mg} / \mathrm{g}$ garam. Kebutuhan tubuh orang dewasa terhadap mineral kalium sebesar 2000 mg/hari (Nirmala, 2010;Brink, 2014) Dari data tersebut garam rich minerals mampu memenuhi kebutuhan kalium seseorang sebesar $4,1 \mathrm{mg} /$ hari, jika mengkonsumsi garam sebanyak $5 \mathrm{~g} /$ hari.

\section{Analisis Kadar Magnesium}

Kadar magnesium pada garam rich minerals sebesar $0.476 \%$ setara dengan $15.87 \mathrm{mg} / \mathrm{g}$

\section{DAFTAR PUSTAKA}

AOAC.1970. Official Method of analysis of The Association of Official Analitycal Chemist. Association of Official Analytical Chemist, washington, DC.

Antonio, Juan. 2010. Methods of preparation of low sodium salt compositions. United Stated patent.

Badan Standarisasi Nasioinal. 1999. SNI 01 3556.1-1999 Garam Gurih. Jakarta.

Badan Standarisasi Nasional.2010. SNI 3556:2010. Garam konsumsi beryodium. Jakarta.

Brink, E.J, Peter, J.A.C.2014. Recommendations for vitamins, Minerals and Trace Element. Netherlands Nutrition Centre. Netherland.

Devi, Nirmala, 2010, Nutrition and Food Gizi untuk Keluarga. Jakarta: PT Kompas Media Nusantara.

Efendy, Makhfud. 2012. Garam Rakyat. Potensi dan Permasalahan. Bangkalan, UTM Press.

Kepmenkes, 2013, Keputusan Menteri Kesehatan Nomor 30 tahun 2013 tentang pencantuman informasi kandungan gula, garam dan lemak serta pesan kesehatan garam. Kebutuhan tubuh orang dewasa terhadap mineral magnesium sekitar $300-500 \mathrm{mg} /$ hari (Nirmala, 2010;Brink, 2014). Dari data tersebut garam rich minerals mampu memenuhi kebutuhan magnesium seseorang sebesar $79.35 \mathrm{mg} /$ hari, jika mengkonsumsi garam sebanyak $5 \mathrm{~g} / \mathrm{hari}$.

\section{KESIMPULAN}

Pada penelitian ini, garam rich minerals diproduksi dari perebusan air laut $(1000 \mathrm{ml})$ bebas kontaminasi dan menghasilkan 34 gram garam rich minerals dengan kadar air sebesar $5 \%, \mathrm{NaCl} 88 \%$, mineral kalium sebesar $0.024 \%$ serta magnesium sebesar $0.476 \%$. Dari data tersebut kadar $\mathrm{NaCl}$ memenuhi SNI syarat mutu garam gurih serta kadar mineral kalium dan magnesium dapat membantu memenuhi angka kecukupan gizi tiap individu.

\section{UCAPAN TERIMA KASIH}

Terima kasih disampaikan kepada Lembaga Penelitian dan Pengabdian Masyarakat Universitas Trunojoyo Madura melalui Program Hibah Penelitian Mandiri UTM 2018.

untuk pangan olahan dan pangan siap saji, Jakarta, Departemen Kesehatan RI.

Nafi, Ahmad. 2014. Pembuatan Garam Gurih jamur Merang Dengan Variasi Lama Hidrolisis dan Lama Fermentasi. Jurnal IImiah Inovasi.

Purbani, Dini. 2013. Proses Pembentukan Kristalisasi Garam. Pusat Riset Wilayah Laut dan sumberdaya nonhayati - Departemen Kelauatan dan Perikanan. Jakarta.

PT.Garam. 2018. Pemahaman dan Penyegaran Proses Kristalisasi Garam. Madura.

Rochmawati, A., Effendi, A. H., dan Hamdani, S. 2015. Pengembangan Metode Analisis Kadar Kalium dalam Daun Kelor (Moringa pleifera) dengan Metode Konduktometri. Prosiding Penelitian SPeSIA Unisba, 591595.

Usiglio, J. 1849. Annales Chem .P.27:92-107 dalam Clarke.FW.1924. The Data of Geochemsitry. US Geol.Survey bulletin. 770219.

Yaswir, Rismawati., et.al., 2012, Fisiologi dan Gangguan Keseimbangan Natrium, Kalium dan Klorida serta Pemeriksaan Laboratorium. Jurnal Kesehatan Andalas. No.1. Hal: 2. 